(RESEARCH ARTICLE)

\title{
Lactate and nitric oxide regulation in male Wistar rats exposed to lead
}

\author{
Adeyomoye Olorunsola Israel 1,* and Adegbite Oluwatobi Samuel 2 \\ ${ }^{1}$ Department of Physiology, Faculty of Basic Medical Sciences, University of Medical Sciences, Ondo City, Ondo State, \\ Nigeria. \\ ${ }^{2}$ Department of Biochemistry, College of Science, Engineering and Technology, Osun State University, Osogbo, Nigeria.
}

Publication history: Received on 22 July 2020; revised on 31 July 2020; accepted on 02 August 2020

Article DOI: https://doi.org/10.30574/wjarr.2020.7.2.0273

\begin{abstract}
Lead is an environmental toxicant that has been implicated in the etiology of many illnesses. It has been reported to cause the constriction of blood vessels. However, it's not clear if this effect is exhibited by regulating the level of vasodilator substances in the blood. This study was designed to investigate the effects of lead exposure on lactate and nitric oxide regulation in male Wistar rats. Eighty (80) Wistar rats were divided into two groups of 40 rats each. Group 1 served as control and was given water while group 2 was exposed to lead acetate (1000 mg/L) for forty days. Five rats were sacrificed from each group $(n=5)$ on days $5,10,15,20,25,30,35$ and 40. Lactate concentration was determined using spectrophotometry procedure. Nitrite concentration was estimated by using the Griess reaction. Lactate concentration increased significantly $(\mathrm{p}<0.05)$ in lead acetate group compared to control in all the durations of exposure. Nitrite concentration decreased significantly $(\mathrm{p}<0.05)$ in lead acetate group compared to control at days 25 , 30,35 and 40 of exposure to lead. The vasodilative effect of lactate may have been suppressed possibly by the overriding vasoconstrictive effect of lead. Lead may have also inhibited the signaling pathways responsible for the production of nitric oxide and relaxation of vascular smooth muscle which enhances blood flow and blood pressure control.
\end{abstract}

Keywords: Lead; Lactate; Nitric oxide; Vasodilative; Vasoconstrictive

\section{Introduction}

Vascular control is crucial in regulating blood flow to different organs of the body [1, 2]. The blood flow to a specific organ is determined by the perfusion pressure and vasomotor tone. The perfusion pressure provides the energy required to overcome the blood flow resistance associated with vessel diameter, hydrodynamic effects at vessel bifurcation, red blood cell deformity, capillary lumen obstructions and viscosity [3]. The vasomotor tone is controlled mainly by myogenic and metabolic mechanisms. The myogenic response occurs when an increase in intraluminal pressure stretches and depolarizes the smooth muscles. This causes the opening of voltage-gated ca ${ }^{2+}$ channels and myosin light chain phosphorylation [4]. The metabolic auto regulation occurs through reactive or active hyperemia. In reactive hyperemia, response to blood flow occurs due to vessel occlusion as occurred during occlusion of the brachial artery [5]. In active hyperemia, response to blood flow occurs through an increase in metabolic demand of the tissues. Vasodilator metabolites are produced by tissues with increase metabolic activities. Examples of these metabolites include $\mathrm{K}^{+}$, ATP, lactate and adenosine. Lactate is produced by most tissues during anaerobic respiration. Tissues with high metabolic rates (gut, brain and skeletal muscle) contribute largely to the increase in production of lactate [6]. Nitric oxide (NO) is a signaling molecule responsible for many physiological processes and it is synthesized by endothelial nitric oxide synthase (eNOS). Nitric oxide causes vasodilation. It increases blood flow and reduces blood pressure. In addition, it prevents tissue damage from a low supply of oxygen [7]. Nitrite is the metabolic end product of nitric oxide and hence, during the estimation of nitric oxide concentration, serum nitrate is reduced to nitrite which is a reliable index for nitric oxide during measurement [8].

\footnotetext{
* Corresponding author: Adeyomoye Olorunsola Israel
} 
Lead is an important environmental toxicant which is abundant and very dangerous to health [9, 10, 11]. Exposure to lead occur mostly through mining, lead gasoline, smelting of iron and its combustion, pottery, brat building, lead-based painting, battery recycling and other industrial processes [12,13]. Although, many nations are diverting from the use of lead to other alternatives however, the use of lead still remains inevitable in many industrial processes [15]. Exposure to lead is known to cause devastating effects on the organs of the body [16]. Studies have shown that exposure to lead is associated with an increase in blood pressure or hypertension which is caused mainly by vasoconstriction of blood vessels $[17,18,19]$. Lactate and nitric oxide are known to cause dilation of blood vessels however, their regulation in the blood after exposure to lead has not been fully elucidated. This study was therefore designed to investigate lactate and nitric oxide regulation in male Wistar rats exposed to lead.

\section{Material and methods}

\subsection{Experimental design}

Eighty (80) male Wistar rats with average weight of $120 \pm 10 \mathrm{~g}$ were purchased from the animal house of the University of Medical Sciences, Ondo State Nigeria. They were housed in well-aerated cages at a temperature of $25^{\circ} \mathrm{C}$ and were allowed to acclimatize for a period of two weeks. The feed and water were given ad-libitum and their beddings changed daily. The experiment was approved by the University of Medical Sciences animal research ethical committee and conducted in compliance with the guidelines recommended by the National Institute of Health [35]. The animals were grouped into two. Animals in group 1 served as the control $(n=40)$ and were given distilled water only while those in group $2(n=40)$ were exposed to $1000 \mathrm{mg} / \mathrm{L}$ of lead acetate. The lead acetate was dissolved in their drinking water daily throughout the period of exposure. The rats were exposed to lead acetate for 40 days and 5 rats from each group were sacrificed on days $5,10,15,20,25,30,35$ and 40.

\subsection{Reagent purchase, blood collection and biochemical assay}

Lead acetate was purchased from Loba, chemical Pvt. Limited, India. The animals were given mild anesthesia (Sodium thiopental $30 \mathrm{~mL} / \mathrm{kg}$ ) and thereafter open up through midline laparotomy. Blood samples were collected through cardiac puncture and thereafter centrifuged at 3000 revolutions per minutes (rpm) to obtain the serum. The animals were sacrificed through cervical dislocation and the sera were stored at a temperature of $-20^{\circ} \mathrm{C}$ prior to assay. Lactate concentration in the serum was assayed using spectrophotometry procedure and their absorbance measured at the specified wavelength [20]. The serum was incubated with nitrate reductase from Aspergillus sp. and with NADPH diluted in $20 \mathrm{mmol} / \mathrm{L}$ Tris buffer (pH 7.6) for $30 \mathrm{~min}$ at room temperature for nitrate reduction. After the reduction, 5\% (w/v) $\mathrm{ZnSO}_{4}$ was added for deproteinization. Then this mixture was centrifuged at $5000 \mathrm{rpm}$ for $\mathrm{I0}$ min. The serum nitrite concentrations were measured by Griess reaction [21].

\subsection{Data analysis}

Data were analyzed using ANOVA to compare values between the durations of exposure. Student t-test was used to compare the values between the two groups. Data were expressed as Mean \pm Standard error of the mean. The probability values that were less than 0.05 were considered to be statistically significant.

\section{Results}

Figure 1 shows lactate concentration in the control and lead exposed rats at the various durations of exposure. In the control group, there was no significant difference in lactate concentration at the various durations of exposure compared to the initial value at day 5. However, in lead acetate $(1000 \mathrm{mg} / \mathrm{L})$, lactate concentration increased significantly at days 25, 30, 35 and 40 compared to the initial value at day 5. Furthermore, lactate concentration increased significantly in lead acetate group compared to control at all the durations of exposure.

Figure 2 shows nitrite concentration in the control and lead exposed rats at the various durations of exposure. In the control group, there was no significant difference in nitrite concentration at the various durations of exposure compared to the initial value at day 5 . However, in lead acetate $(1000 \mathrm{mg} / \mathrm{L})$, nitrite concentration decreased significantly at days 30 and 40 compared to the initial value at day 5. Furthermore, nitrite concentration decreased significantly in lead acetate group compared to control at days 25, 30, 35 and 40 of exposure to lead. 


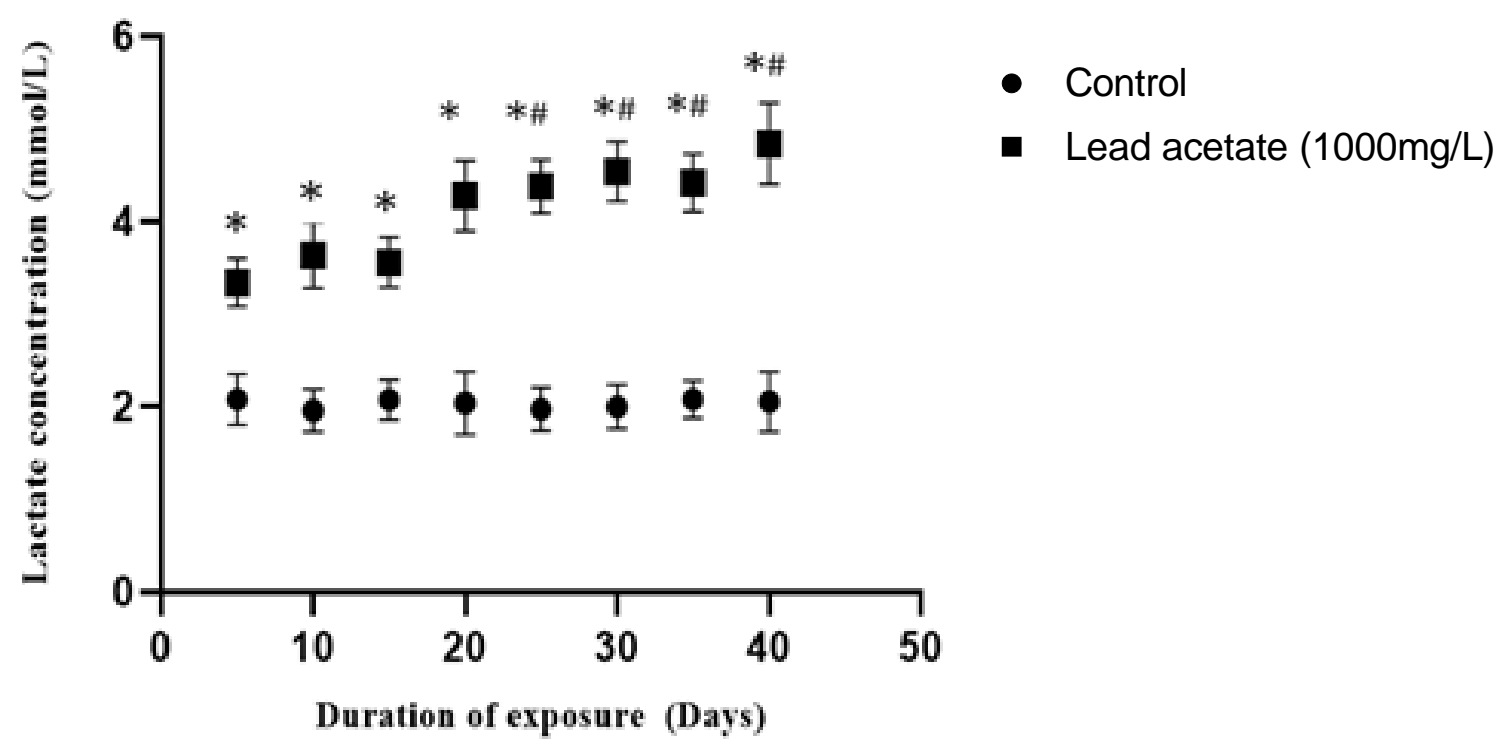

Figure. 1 Lactate concentration in the control and lead exposed rats. * indicates value that was significantly different from control while \# indicates value that was significantly different from the initial value at day $5(n=5)$.

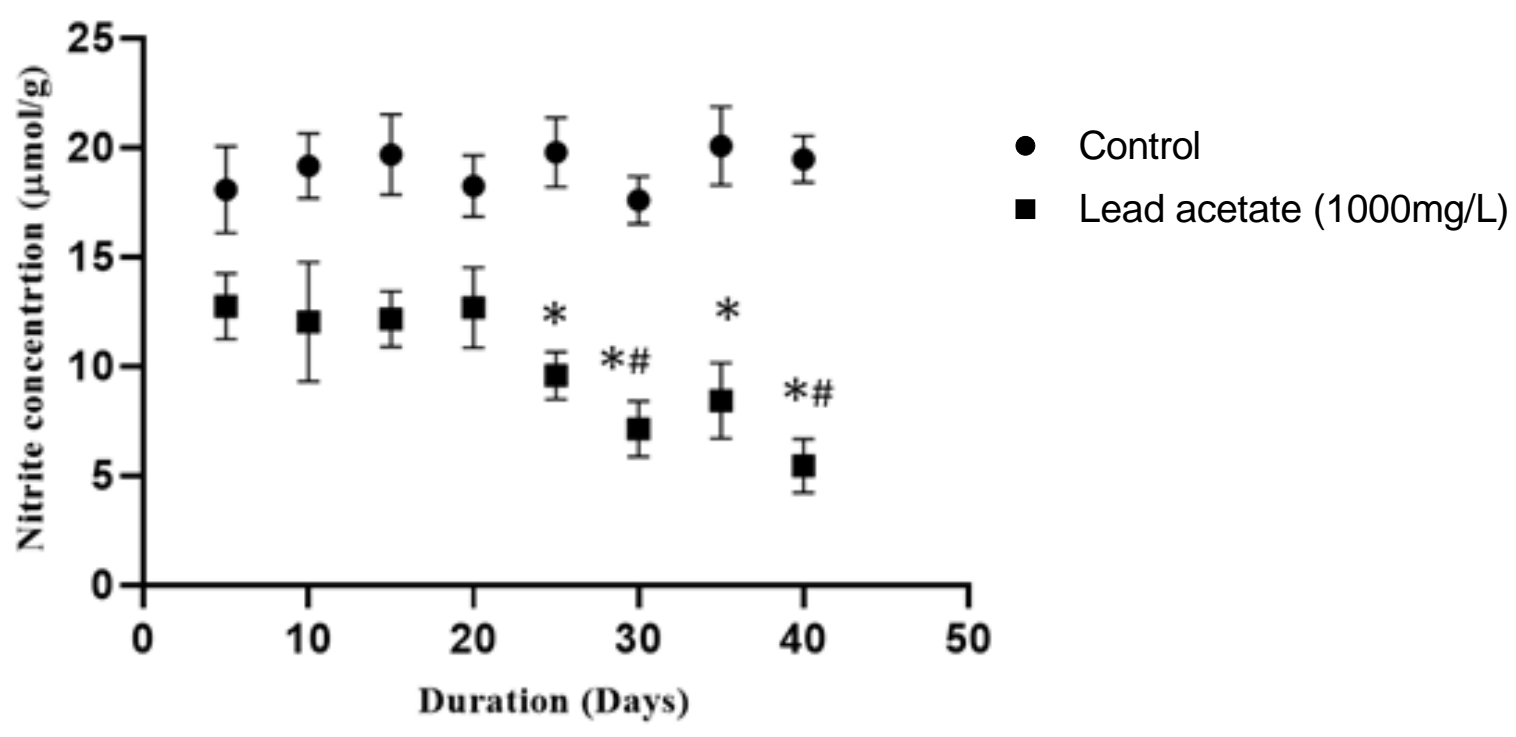

Figure 2 Nitrite concentration in the control and lead exposed rats. * indicates value that was significantly different from control while \# indicates value that was different from the initial value at day $5(n=5)$.

\section{Discussion}

Lead is an environmental toxicant and several studies have demonstrated links between lead exposure and cardiovascular diseases [22, 23, 24]. Exposure to lead has been shown to cause an increase in arterial pressure which occurs through vasoconstriction [25]. The present study investigated how lactate and nitric oxide were regulated during vasoconstriction caused by lead exposure in Wistar rats.

During glycolysis, glucose is converted to pyruvate. This is further converted to either acetyl CoA in the presence of oxygen (aerobic respiration) or to lactic acid during anaerobic respiration. Deprotonation of lactic acid gives rise to lactate although, the two are often used interchangeably. The significant increase in lactate production may be as a result of hypoxia caused by vasoconstriction due to exposure to lead. Lactate concentration was high throughout the 
period of exposure thus suggesting an increase in cellular metabolism [26]. However, most of the lactate produced may not have been allowed to leave the cell and be excreted. This suggests that the vasoconstriction caused by lead exposure may have an overriding effect on the vasodilative action of lactate. The hyperlactatemia observed from this study is consistent with the reports of Barrie et al. 2006 [27] who also stated that an increase in the blood lactate level could be due to tissue hypoxia which results in faster production than removal. However, an increase in oxygen delivery to tissue may likely reverse these effects. The observed hyperlactatemia in the lead acetate (1000 mg/L) group could result in a decrease in the $\mathrm{pH}$ of blood due to the continuous release of hydrogen ions which may eventually cause acidosis [28].

Nitric oxide has a dual function. At moderate concentration, it's responsible for many physiological processes [29]. However, at high concentration it could cause pathological conditions [30]. When endothelial nitric oxide isoform (eNOS) is stimulated, it produces nitric oxide which diffuses across the cell membrane to the target cell. It activates guanylyl cyclase which produces cyclic guanosine monophosphate (cGMP) from guanosine triphosphate (GTP). The cGMP therefore, catalysis the phosphorylation of different proteins and activation or inhibition of ion channels [31]. The resultant effects of this stimulation are the relaxation of smooth muscle cells, increase endothelial permeability, cardiac protection and many others [32]. The observed decrease in nitrite concentration throughout the duration of exposure could be due to the ability of lead to inhibit the signaling processes involved in nitric oxide production. This causes the unavailability of nitric oxide to cause the relaxation of smooth muscle and vasodilation [33]. Lead could also have acted by increasing intracellular calcium ions which causes contraction and vasoconstriction [34]. These effects of lead may impair the regulation of blood flow and blood pressure.

\section{Conclusion}

The male Wistar rats exposed to lead acetate $(1000 \mathrm{mg} / \mathrm{L})$ had increase in lactate and decrease in nitric oxide production. These effects of lead, may be due to its overriding vasoconstrictive effect and inhibition of the signaling pathways responsible for the relaxation of vascular smooth muscle which enhances blood flow and blood pressure control.

\section{Compliance with ethical standards}

\section{Acknowledgments}

The authors appreciate Mr Adebowale (Brain Bridge Institute, Ilorin, Nigeria) for supplying the laboratory assay kits

\section{Disclosure of conflict of interest}

The authors declare that they have no conflict of interest.

\section{Statement of ethical approval}

The study was approved by the local review committee and conducted in line with the guidelines of the National Institute of Health.

\section{References}

[1] Park S, Nguyen NB, Pezhouman A and Ardehali R. (2019). Cardiac fibrosis: potential therapeutic targets. Transl Res. 209, 121-137.

[2] Elkin HK and Winter A. (2018). Grounding Patients with Hypertension Improves Blood Pressure: A Case History Series Study. Altern Ther Health Med, 24(6), 46-50.

[3] Hambrecht R, Adams V, Erbs S, Linke A, Krankel N, Shu Y, et al. (2003). Regular physical activity improves endothelial function in patients with coronary artery disease by increasing phosphorylation of endothelial nitric oxide synthase. Circulation, 107, 3152-8.

[4] Cuttle MF, Tsujimoto T, Forsythe ID and Takahashi T. (1998). Facilitation of the presynaptic calcium current at an auditory synapse in rat brainstem. J Physiol, 512, 723-729.

[5] Shaw RS. (1956). A more aggressive approach toward the restoration of blood flow in acute arterial insufficiency. Surg Gynecol Obstet, 103(3), 279-288.

[6] Brooks GA. (2000). Intra-and extra-cellular lactate shuttles. Med. Sci. Sports. Exerc, 32, 790-799. 
[7] Stamler JS, Lamas S and Fang FC. (2001). Nitrosylation. The prototypic redox-based signaling mechanism. Cell. 106, 675-683.

[8] Ylldırım 0. (2003). Changes in Nitric Oxide Level of Different Tissues in Diabetic Rats, Biotechnology \& Biotechnological Equipment, 17(1), 131-135.

[9] Centers for Disease Control and Prevention (CDC) CDC. (2009). Fourth National Report on Human Exposure to Environmental Chemicals. Atlanta, GA: US Department of Health and Human Services.

[10] Chisolm J and Harrison H. (1956). The Exposure of Children to Lead. J Am Acad Pediatrics, 1, 943-958.

[11] Flora G, Gupta D and Tiwari A. (2012). Toxicity of lead: A review with recent updates. Interdiscip Toxicol. 5, 4758.

[12] Levin SM and Goldberg M. (2000). Clinical evaluation and management of lead-exposed construction workers. Am J Ind Med. 37, 23-43.

[13] Adeyomoye OI and Adewumi NA. (2019). Lead exposure causes alteration of haematological indices in adult female Wistar rats, Asian Journal of Pharmaceutical Research and Development, 7(6), 30-34.

[14] Rastogi SK. (2008). Renal effects of environmental and occupational lead exposure. Indian J Occup Environ Med, 12, 103-6.

[15] Huang F and Schneider, J. (2004). Effects of lead exposure on proliferation and differentiation of neural stem cells derived from different regions of embryonic rat brain. Neurotoxicology, 25, 1001-1012.

[16] Kasten-Jolly J, Pabello N, Bolivar VJ and Lawrence DA. (2012). Developmental lead effects on behavior and brain gene expression in male and female BALB/cAnNTac mice. Neurotoxicology, 33, 1005-1020.

[17] Schwartz J. (1995). Lead, blood pressure, and cardiovascular disease in men. Arch Environ Health, 50, 31-37.

[18] Shelkovnikov SA and Gonick HC. (2001). Influence of lead on rat thoracic aorta contraction and relaxation. Am J Hypertens 14, 873-878.

[19] Simons TJ. (1993). Lead-calcium interactions in cellular lead toxicity. Neurotoxicology, 14, 77-86.

[20] BrandtMichael HB. (1980). Spectrophotometric assay for d-(-)-lactate in plasma. Analytical Biochemistry, (102), 39-46.

[21] Pelletier MM. (2006). The measurement of blood and plasma nitrite by chemiluminescence: pitfalls and solutions. Free Radic Biol Med, 41(4), 541-8.

[22] Lundstrom NG, Nordberg G, Englyst V, Gerhardsson L, Hagmar L, Jin T, et al. (1997). Cumulative lead exposure in relation to mortality and lung cancer morbidity in a cohort of primary smelter workers. Scand J Work Environ Health, 23, 24-30.

[23] Muzi G, Murgia N, Dell'Omo M, Fiordi T, Sposini F, Argentino A, et al. (2005). Effects of inorganic lead exposure on the autonomic nervous system and on the variability of heart rate among workers at a battery plant. G Ital Med Lav Ergon, 27(1), 46-50.

[24] Saric M. (1981). Ischemic heart disease, circulatory diseases and kidney diseases in a population living near a lead smelter. Arh Hig Rada Toksikol, 32, 3-19.

[25] Sharifi MA, Darabi R, Akbarloo N, Larijani B and Khoshbaten A. (2004). Investigation of circulatory and tissue ACE activity during development of lead-induced hypertension. Toxicol Lett, 153, 233-238.

[26] Dawson AG. (1979). Oxidation of cytosolic NADH formed during aerobic metabolism in mammalian cells. Trends Biochem Sci, 4, 171-176.

[27] Barrie P. (2006). Lactate physiology in health and disease. Continuing Education in Anaesthesia, Critical Care \& Pain, 6, 3.

[28] Gillies RJ, Pilot C, Marunaka Y and Fais S. (2019). Targeting acidity in cancer and diabetes. Biochim Biophys Acta Rev Cancer, (2), 273-280.

[29] Palmer RM, Ferrige AG and Moncada S. (1987). Nitric oxide release accounts for the biological activity of endothelium-derived relaxing factor. Nature, 327(6122), 524-526.

[30] Moncada S, Palmer RM and Higgs EA. (1991). Nitric oxide: physiology, pathophysiology, and pharmacology. Pharmacol Rev. 43(2), 109-142. 
[31] Bruckdorfer R. (2005). The basics about nitric oxide. Mol Aspects Med, 26(1-2), 3-31.

[32] Arzumanian V, Stankevicius E, Laukeviciene A and Kevelaitis E. (2003). Azoto oksido sinteze ir veikimo mechanizmai lastelese. Mechanisms of nitric oxide synthesis and action in cells]. Medicina (Kaunas), 39(6), 535541.

[33] Lowenstein CJ and Synder SH. (1992). Nitric oxide, a novel biologial messenger. Cell, 70, 705-707.

[34] Webb RC. (2003). Smooth muscle contraction and relaxation. Adv Physiol Educ, 27(1-4).

[35] Adeyomoye OI and Adewoye EO. (2018). Preliminary assessments and renoprotective effects of methanol extract of Parquetina nigrescens (Africa Parquetina) in diabeticWistar rats. Asian Journal of Research in Medical and Pharmaceutical Sciences, 3(4), 1-10.

\section{How to cite this article}

Adeyomoye OI and Adegbite OS. (2020). Lactate and nitric oxide regulations in male Wistar rats exposed to lead. World Journal of Advanced Research and Reviews, 7(2), 01-06. 